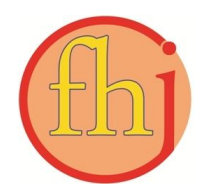

Faletehan Health Journal, 6 (1) (2019) 11-15

www. journal.Ippm-stikesfa.ac.id/ojs/index.php/FHJ

ISSN 2088-673X | e-ISSN 2597-8667

\title{
Rebusan Buah Asam Dan Jahe Sebagai Upaya Mengurangi Dismenore
}

\author{
Trio Gustin Rahayu ${ }^{1^{*}}$ \\ 1Program Studi DIII Keperawatan STIKes Faletehan Serang, Banten, Indonesia \\ *Corresponding Author: triogustin@gmail.com
}

\begin{abstract}
Abstrak
Setiap wanita sehat akan mengalami siklus menstruasi pada setiap bulannya. Lebih dari $50 \%$ wanita di setiap negara mengalami nyeri menstruasi atau dismenore. Cara mengatasi dismenore yang aman adalah dengan rebusan herbal. Tujuan penelitian ini untuk mengetahui perbedaan efektivitas asam dan jahe dalam mengurangi dismenore. Desain penelitian ini menggunakan quasi eksperimen pre dan post test dengan sampel 30 mahasiswa yang dibagi dua kelompok. Masing-masing kelompok diberikan rebusan asam dan rebusan jahe pada pagi dan sore hari selama menstruasi hari pertama sampai hari ketiga. Responden dilakukan pengkajian nyeri sebelum dan sesudah diberikan intervensi. Analisis dengan menggunakan independent T-Test. Hasil didapatkan responden yang diberikan rebusan buah asam sebelum intervensi $60 \%$ mengalami nyeri sedang dan setelah intervensi $87 \%$ mengalami nyeri ringan, sedangkan responden yang diberikan rebusan jahe sebelum intervensi $67 \%$ mengalami nyeri sedang dan setelah intervensi $73 \%$ mengalami nyeri ringan sehingga disimpulkan rebusan jahe lebih efektif dibandingkan rebusan asam. Diharapkan peneliti selanjutnya melakukan penelitian mengurangi dismenore dengan rebusan herbal selain buah asam dan jahe.

Kata Kunci: Dismenore, Jahe, Rebusan Buah Asam
\end{abstract}

\begin{abstract}
Every healthy woman will get experience a menstruation cycle every month. More than $50 \%$ of women in each country experience dysmenorrhea. One way to deal with dysmenorrhea is by using decoction. The purpose of this study was to determine the differences of the tamarind decoction and ginger decoction in reducing on dysmenorrhea. The design of this study was quasi experiment pre and post test with a sample of 30 students which was divided into two groups. Each group was given extract water of tamarind and ginger decoction in the morning and evening during menstruation first day to third day. Respondents were assessed for pain before and after intervention. Data was analyzed by using independent T-Test. The results of the study showed that respondents who were given tamarind decoction before intervention $60 \%$ experienced moderate pain and after the intervention $87 \%$ experienced mild pain, while respondents who were given ginger decoction before intervention 67\% experienced moderate pain and after intervention $73 \%$ experienced mild pain. This study concluded that ginger decoction was more effective than tamarind decoction. It is recommended that future researchers conduct research to reduce dysmenorrhea with another herbal besides tamarind decoction or ginger decoction.
\end{abstract}

Keywords: Dysmenorrhea, Ginger Decoction, Tamarind Decoction 


\section{Pendahuluan}

Menstruasi merupakan peristiwa pendarahan secara periodik dan siklik (bulanan) dari rahim disertai pelepasan selaput lendir rahim (endometrium) melalui vagina pada wanita yang seksual dewasa. Setiap wanita sehat yang tidak sedang hamil dan belum menopause akan mendapat menstruasi pada setiap bulannya. Dalam keadaan normal lamanya haid berkisar antara 3-7 hari dan rata-rata berulang setiap 28 hari. Rasa nyeri saat haid merupakan keluhan ginekologi yang paling umum dan banyak dialami oleh wanita. Dismenore adalah nyeri haid yang merupakan suatu gejala dan bukan suatu penyakit (Baziad, 2003). Dismenore adalah sakit saat menstruasi sampe dapat mengganggu aktivitas sehari- hari (Manuaba, 2001)

Sekitar satu miliar manusia atau setiap $1 \mathrm{di}$ antara 6 penduduk dunia adalah remaja. Sebanyak $85 \%$ diantaranya hidup di negara berkembang (Kusmiran, 2012). Berdasarkan kriteria WHO umur remaja berkisar antara 10-19 tahun. Angka kejadian dismenore di dunia cukup besar, rata-rata lebih dari $50 \%$ perempuan di setiap negara mengalami dismenore. Berdasarkan data diperkirakan 45-90\% remaja di Amerika Serikat mengalami dismenore, di Swedia 90\% wanita kurang dari 19 tahun dan $67 \%$ berusia 24 tahun dilaporkan mengalami dismenore. Sedangkan di Indonesia remaja yang mengalami dismenore sebesar 64,25\% (Wilis, 2011). Berdasarkan studi epidemiologi pada populasi remaja (berusia 12-17 tahun) di Amerika Serikat dilaporkan bahwa prevalensi dismenore mencapai $59,7 \%$. Studi ini juga melaporkan bahwa dismenore menyebabkan $14 \%$ remaja sering tidak masuk sekolah (Bonde, 2014)

Data dari WHO didapatkan bahwa kejadian wanita yang mengalami dismenore berat sebesar 1.769.425 jiwa (90\%), 10-15\% diantaranya mengalami dismenore berat. Hal ini didukung dengan penelitian yang telah dilakukan diberbagai Negara dengan hasil yang mencengangkan, dimana kejadian dismenore primer disetiap negara dilaporkan lebih dari 50\% (Susilawati, 2013)

Sementara di Indonesia angka kejadian diperkirakan $55 \%$ wanita usia produktif yang tersiksa karena dismenore. Angka kejadian dismenore berkisar $45-95 \%$ di kalangan wanita usia produktif. Dengan angka kejadian dismenore primer 54,89\% sisanya penderita sekunder
(Proverawati, 2009). Gumangsari menjelaskan bahwa $90 \%$ perempuan Indonesia pernah mengalami dismenore. Hasil penelitian tersebut juga menjelaskan bahwa lebih banyak perempuan yang mengalami dismenore tidak melaporkan atau berkunjung ke dokter (Gumangsari, 2014).

Penggunaan obat-obatan untuk mengurangi dismenore sangat beresiko karena efek samping jika digunakan secara bebas dan berulang tanpa pengawasan dari dokter. Berbagai penelitian menemukan beberapa alternative pengobatan untuk mengatasi dismenore yaitu dengan rebusan pengganti maupun rebusan pelengkap yang lebih aman seperti rebusan herbal, rebusan akupuntur, rebusan tingkah laku dan aroma rebusan (Suciani, 2004). Menurut penelitian (Suparmi, 2016) terjadi penurunan skala nyeri dismenore primer sesudah diberikan rebusan jahe merah dan buah asam pada kelompok perlakuan pada hari ke satu sampai ke tiga. Pemberian rebusan jahe merah dan buah asam selama lima hari efektif terhadap penurunan skala nyeri pada dismenore.

Terdapat perbedaan bermakna penurunan intesitas nyeri sebelum dan sesudah diberikan intervensi rebusan jahe. Prosentase terbesar intensitas nyeri sebelum dilakukan intervensi adalah nyeri sedang $(81 \%)$, dan prosentase terbesar intensitas nyeri sesudah dilakukan intervensi adalah nyeri ringan $(73 \%)$. Sehingga rebusan jahe dapat dijadikan salah satu pilihan pengobatan non famakologi (herbal) untuk mengurangi nyeri dismenore (Rahayu \& Nujulah, 2017)

Adanya pengaruh rebusan jahe terhadap dismenore dikarenakan jahe memiliki kandungan oleoresin jahe terdiri atas gingerol dan zingiberen, shagaol, minyak atsiri dan resin dapat menghambat kerja enzim didalam sikus COX. Sehingga dapat menghambat pelepasan enzim tersebut menuju prostaglandin yang menyebabkan inflamasi. Selain itu juga jahe merah (zingiber officinale) dapat menghambat terjadinya kontraksi pada uterus yang dapat menyebabkan nyeri pada saat menstruasi (Mutiara \& Pratiwi, 2017).

Berdasarkan hasil studi pendahuluan yang dilakukan terhadap sepuluh mahasiswi tingkat dua, delapan diantaranya mengalami dismenore. Selama ini mereka hanya mengandalkan minum obat-obatan pada saat mengalami nyeri menstruasi dimana apabila hal ini terus dilakukan pada saat menstruasi maka akan mempunyai dampak yang tidak baik bagi kesehatan. Upaya mengurangi 
Faletehan Health Journal, 6 (1) (2019) 11-15 www. journal.Ippm-stikesfa.ac.id/ojs/index.php/FHJ ISSN 2088-673X | 2597-8667

dismenore yang tidak berbahaya adalah menggunakan rebusan herbal seperti rebusan jahe dan buah asam. Jahe dan buah asam sangat mudah didapatkan terutama oleh mahasiswa yang disibukkan dengan perkuliahan. Mahasiswa dapat merebusnya sendiri atau bisa membeli ditukang jamu keliling yang hampir di setiap daerah dapat ditemukan.

\section{Metode Penelitian}

Metode penelitian yang digunakan adalah quasi eksperimen dengan rancangan pre and post tes design yaitu responden sebelum dan sesudah dilakukan intervensi diberikan pengukuran terlebih dahulu. Populasi dalam penelitian ini adalah mahasisa tingkat dua Akadami Keperawatan STIKes Faletehan Serang. Teknik sampling dengan menggunakan purposive sampling yaitu 30 mahasiswa yang sesuai dengan kriteria inklusi. Adapun kriteria inklusi dalam penelitian ini adalah mahasiswa yang mengalami haid dan dismenore selama penelitian berlangsung. Responden di bagi menjadi dua kelompok yaitu kelompok 1 dan kelompok 2 masing-masing kelompok sebanyak 15 mahasiswa. Kelompok 1 diberikan rebusan asam dan kelompok 2 diberikan rebusan jahe. Responden kelompok 1 dan kelompok 2 masingmasing rebusan diberikan selama 3 hari pada saat menstruasi hari pertama sampai hari ketiga. Setiap hari responden diberikan rebusan sebanyak 1 cup gelas plastik $(500 \mathrm{ml})$ yang diminum 2 kali yaitu pagi dan sore. Sebelum diberikan rebusan buah asam atau jahe responden terlebih dahulu dilakukan pengkajian skala nyeri. Setelah pemberian rebusan selama 3 hari kemudian dilakukan pengkajian nyeri kembali untuk mengetahui perbedaan skala nyeri sebelum dan sesudah diberikan intervensi pemberian rebusan buah asam dan jahe. Analisis penelitian dengan menggunakan independent $T$-Test dengan terlebih dahulu menggunakan uji normalitas data. Hasil dari uji normalitas data adalah data yang digunakan dalam penelitian adalah normal.

\section{Hasil dan Pembahasan}

Berdasarkan tabel 1 menunjukkan bahwa ratarata usia responden adalah 19 tahun dengan usia paling muda 18 tahun dan usia paling tua 20 tahun. Sedangkan usia menarche pertama responden ratarata 13 tahun dengan usia termuda 12 tahun dan usia tertua 15 tahun. Hasil ini sesuai dengan penelitian sebelumnya yang dilakukan (Sugiharti
\& Sukmaningtyas, 2017) bahwa rata-rata usia responden adalah 18 tahun dengan usia minimum 17 tahun dan maximum 21 tahun. Penelitian lain oleh (Rahayu \& Nujulah, 2017) dapat dilihat bahwa umur rata-rata responden yang mengalami dismenore adalah 19 tahun. Penelitian (Ekawati, 2017) didapatkan bahwa hampir seluruh atau $85,6 \%$ responden usia menarche 9-12 tahun dan sebagian kecil atau 14,4\% mahasiswi usia menarche 13-16 tahun.

Berdasarkan tabel 2 menunjukkan bahwa sebelum diberikan rebusan asam $60 \%$ responden mengalami nyeri sedang dan $40 \%$ mengalami nyeri ringan. Hal ini sesuai dengan penelitian penelitian (Ekawati, 2017) bahwa sebelum diberikan rebusan buah asam hampir seluruh atau $86 \%$ responden mengalami nyeri sedang dan sebagian kecil atau $14 \%$ nyeri berat. Penelitian diketahui bahwa dari 44 responden, responden dengan derajat dismenore sebelum minum rebusan buah asam termasuk kategori ringan sejumlah $33(75 \%)$ responden dan responden dengan tingkat dismenore yang termasuk kategori sedang sejumlah 11 (25\%) responden.

Tabel 1. Distribusi Frekuensi Responden

\begin{tabular}{lccc}
\hline \multicolumn{1}{c}{ Karakteristik } & Mean & SD & $\begin{array}{c}\text { Min- } \\
\text { Max }\end{array}$ \\
\hline Umur & 19 & 0.78 & $18-20$ \\
Umur Pertama Haid & 13 & 0.94 & $12-15$ \\
\hline
\end{tabular}

Tabel 2. Distribusi Responden Sebelum diberikan Rebusan Asam

\begin{tabular}{lcc}
\hline \multicolumn{1}{c}{ Rentang Nyeri } & F & \% \\
\hline Ringan & 6 & 40 \\
\hline Sedang & 9 & 60 \\
\hline Berat & 0 & 0 \\
\hline
\end{tabular}

Tabel 3. Distribusi Responden Setelah Diberikan Rebusan Asam

\begin{tabular}{lcc}
\hline \multicolumn{1}{c}{ Rentang Nyeri } & F & \% \\
\hline Ringan & 13 & 87 \\
\hline Sedang & 2 & 13 \\
\hline Berat & 0 & 0 \\
\hline
\end{tabular}


Berdasarkan tabel 3 diatas menunjukkan bahwa sesudah diberikan rebusan buah asam hampir seluruh atau $87 \%$ responden mengalami nyeri ringan dan sebagian kecil atau $13 \%$ mengalami nyeri sedang. Hal ini sesuai dengan penelitian (Winarso, 2014) bahwa responden yang tidak mengalami dismenore sesedah minum rebusan buah asam sejumlah $17(38,6 \%)$, yang termasuk kategori ringan sejumlah $21(47,7 \%)$ responden dan responden dengan tingkat nyeri dismenore termasuk kategori sedang sejumlah 6 $(13,6 \%)$ responden.

Berdasarkan tabel 4 menunjukkan bahwa sebelum diberikan rebusan jahe $27 \%$ mengalami nyeri ringan, $67 \%$ responden mengalami nyeri sedang dan 6\% mengalami nyeri berat. Penelitian (Rahayu \& Nujulah, 2017) mengatakan bahwa internsitas nyeri sebelum dilakukan intervensi pemberian rebusan jahe adalah responden yang mengalami nyeri ringan $4 \%$, nyeri sedang $81 \%$ dan berat $4 \%$.

Berdasarkan tabel 5 menunjukkan bahwa sesudah diberikan rebusan jahe lebih dari sebagian atau $73 \%$ responden mengalami nyeri ringan dan sebagian kecil atau $27 \%$ nyeri sedang. Penelitian (Rahayu \& Nujulah, 2017) mengatakan bahwa internsitas nyeri sebeum dilakukan intervensi pemberian rebusan jahe adalah responden yang mengalami nyeri ringan $73 \%$, nyeri sedang $19 \%$ dan berat $8 \%$.

Berdasarkan tabel 6 menunjukkan hasil analisis uji independen T-Test untuk mengetahui perbedaan efektivitas rebusan buah asam dengan jahe didapatkan nilai $\mathrm{P}=0,000$ pada taraf signifikan $\mathrm{p}=0,05$, sehingga dapat ditarik kesimpulan bahwa H1 diterima, artinya ada perbedaan pemberian rebusan buah asam dengan rebusan jahe terhadap penurunan dismenore. Dimana rebusan jahe lebih efektif dibandingkan pemberian rebusan buah asam untuk menurunkan dismenore. Hal ini di buktikan dengan rerata penurunan nyeri pada kelompok yang diberikan rebusan buah asam adalah 0.04 sedangkan pada kelompok yang diberikan rebusan jahe 0,08 . Hasil dari intervensi ini sesuai dengan penelitian Sugiharti dan Sukmaningtyas yang menjelaskan bahwa sebagian besar responden mengalami penurunan nyeri haid setelah diberikan rebusan jahe (Sugiharti \& Sukmaningtyas, 2017).

Penelitian (Rahayu \& Nujulah, 2017) didapatkan hasil bahwa rata-rata nyeri sebelum diberikan intervensi rebusan jahe yaitu sebesar 2,12 dan sesudah diberikan intervensi rebusan jahe adalah sebesar 1,35 . Penurunan nilai rata-rata intensitas nyeri pada responden sebelum dan sesudah adalah sebesar 0,77 sehingga dapat disimpulkan bahwa terjadi penurunan intensitas nyeri sebelum dan sesudah diberikan intervensi jahe.

Tabel 4. Distribusi Responden Sebelum Diberikan Rebusan Jahe

\begin{tabular}{lcc}
\hline \multicolumn{1}{c}{ Rentang Nyeri } & F & \% \\
\hline Ringan & 4 & 27 \\
\hline Sedang & 10 & 67 \\
\hline Berat & 1 & 6 \\
\hline
\end{tabular}

Tabel 5. Distribusi Responden Setelah Diberikan Rebusan Jahe

\begin{tabular}{lcc}
\hline \multicolumn{1}{c}{ Rentang Nyeri } & F & \% \\
\hline Ringan & 11 & 73 \\
\hline Sedang & 4 & 27 \\
\hline Berat & 0 & 0 \\
\hline
\end{tabular}

Tabel 6. Perbedaan Efektivitas Pemberian Rebusan Asam dan Jahe

\begin{tabular}{|c|c|c|c|c|c|}
\hline Skala Nyeri & $\mathbf{F}$ & Mean & SD & Beda SD & P value \\
\hline Kelompok asam & 15 & & & \multirow{3}{*}{0.040} & \multirow{6}{*}{0,000} \\
\hline Pre test & & 3.73 & 1.100 & & \\
\hline Post test & & 2.17 & 1.060 & & \\
\hline Kelompok jahe & 15 & & & & \\
\hline Pre test & & 4.47 & 1.246 & \multirow{2}{*}{0.089} & \\
\hline Post test & & 2.93 & 1.335 & & \\
\hline
\end{tabular}


Faletehan Health Journal, 6 (1) (2019) 11-15 www. journal.Ippm-stikesfa.ac.id/ojs/index.php/FHJ ISSN 2088-673X | 2597-8667

Jahe sendiri mengandung gingerol yang mampu memblokir prostaglandin. Penelitian menunjukan bahwa jahe memiliki efektivitas yang sama dengan asam mefenamat dan ibuprofen dalam mengurangi rasa nyeri pada nyeri haid primer. Selain itu tidak ditemukan efek samping yang parah dari jahe (Corwin, 2009). Jahe memiliki efektivitas yang sama dengan ibuprofen dalam mengurangi nyeri. Secara umum ibuprofen dikenal sangat cepat dan efektif diserap setelah pemberian peroral. Puncak konsentrasi di dalam plasma sangat singkat yaitu antara 15 menit-1 jam. Kerja dari ibuprofen pun sama dengan jahe yaitu dengan menghambat sintesis prostaglandin. Obat-obat atau herbal yang sejenis dengan ibuprofen sangat mudah diabsorbsi oleh sistem gastrointestinal. Waktu paruh obat adalah waktu yang diperlukan obat untuk di metabolisme. Waktu paruh ibuprofen relatif singkat (Corwin, 2009)

\section{Simpulan}

Kesimpulan dalam penelitian ini adalah sebelum diberikan rebusan buah asam $60 \%$ responden mengalami nyeri sedang dan sesudahnya $87 \%$ responden mengalami nyeri ringan. Pada responden sebelum diberikan rebusan jahe $67 \%$ mengalami nyeri sedang dan sesudah diberikan $73 \%$ mengalami nyeri ringan. Terdapat perbedaan pemberian rebusan buah asam dengan rebusan jahe terhadap penurunan dismenore. Rebusan jahe lebih efektif untuk menurunkan dismenore.

\section{Referensi}

Baziad, A. (2003). Endokrinologi Ginekologi. Jakarta: Aesculapius.

Bonde, d. (2014). Pengaruh Kompres Panas terhadap Penurunan Derajat Nyeri Haid pada siswi SMA dan SMK Yadika Kopandakan II. Jurnal Fisika Fakultas Kedokteran Universitas Sam Ratulangi Manado.

Corwin, E. J. (2009). Buku Saku Patofisiologi. Jakarta: Aditya Media.

Ekawati, H. (2017). Perbedaan Efektifitas Pemberian Rebusan Jahe dan Kunyit Asam terhadap Penurunan Disminorea pada Mahasiswi Semester VII Keperawatan STIKes Muhammadiyah Lamongan. Jurnal Surya .
Gumangsari, N. M. (2014). Pengaruh Massage Counterpressure terhadap Penurunan Tingkat Nyeri Haid pada Remaja Putri di SMAN 2 Ungaran Kabupaten Semarang.

Kusmiran, E. (2012). Kesehatan Reproduks Remaja dan Wanita. Jakarta: Salemba Medika.

Manuaba, I. (2001). Kapita Selekta Penatalaksanaan Rutin Obstetric Ginekologi dan $K B$. Jakarta: EGC.

Mutiara, H., \& Pratiwi, L. A. (2017). Pengaruh Jahe terhadap Nyeri Saat Menstruasi. Medical Journal of Lampung University .

Proverawati, A. M. (2009). Menarche Menstruasi Pertama Penuh Makna. Yogyakarta: Nuha Medika.

Rahayu, K. D., \& Nujulah, L. (2017). Efektifitas Pemberian Ekstrak Jahe terhadap Intensitas Dismenore pada Mahasiswi Akademi Kebidanan Sakinah Pasuruan. Jurnal Kesehatan STIKES BHAKTI HUSADA MULIA .

Suciani, S. (2004). Efektivitas Pemberian Rebusan Kunyit Asam terhadap Penurunan Dismenore.

Sugiharti, R. K., \& Sukmaningtyas, W. (2017). Pengaruh Minuman Rempah Jahe Asam terhadap Penurunan Skala Nyeri Haid Primer pada Remaja. Seminar Nasional dan Presentasi Hasil-Hasil Penelitian Pengabdian Masyarakat.

Suparmi, A. R. (2016). Upaya Mengurangi Dismenore Primer dengan Ekstrak Jahe Asam Jawa pada Mahasiswi Kebidanan STIKES Aisyiyah Surakarta. GASTER .

Susilawati, G. (2013). Hubungan Umur, Paritas dan Status Gizi dengan Kejadian Dismenore pada Wanita Usia Subur di Gampang Baitussalam Ceh Besar. Skripsi .

Wilis, A. R. (2011). Pengaruh Pemberian Air Rebusan Jahe terhadap Intensitas Nyeri Haid pada Mahasiswa Semester 7 Stikes Aisyiyah Yogyakarta. ANGGI RETNO WILIS (070201049).

Winarso, A. (2014). Pengaruh Minum Kunyit Asam terhadap Penurunan Tingkat Nyeri Disminorea pada Siswi di Madrasah Tsanawiyah Negeri Jatinom Klaten. 